\title{
A Comparative Study of Static and Kinetic Frictional Resistance during the Sliding of Arch Wires through Orthodontic Brackets, using Different Methods of Ligation, in the Dry State
}

Armando Montesinos F*

Department of Orthodontics, Postgraduate Studies and Research Division, Odontology Faculty, National Autonomous University of Mexico, Mexico

\begin{abstract}
Frictional resistance is crucial between arch wires and brackets, sometimes benefic and in other clinical situations undesirable, making difficult to apply orthodontic forces efficiently. There are many variables that influence frictional resistance and the method of ligation is one of the most important. The objective of this study was to compare static and kinetic frictional resistance during the sliding of 0.016 " and 0.016 " $\times 0.022$ " SS arch wires (upper and lower) through orthodontic brackets, using different methods of ligation (elastomeric ties, low friction elastomeric ties, stainless steel ligature, active and passive self-ligating brackets). It was developed an original methodology to evaluate frictional resistance to sliding with different methods of ligation. The results showed that the method of ligation that generated the highest static and kinetic frictional resistance values was elastomeric ties, followed by low friction elastomeric ties>metallic ligature> and at last self-ligating brackets for all arch wires.
\end{abstract}

Keywords: Friction; Sliding; Frictional resistance; Method of ligation; Static frictional resistance; Kinetic Frictional resistance

\section{Introduction}

Contemporary Orthodontics objectives are: function, aesthetics, periodontal integrity and stability. Different authors have tried to explain the biological response to an orthodontic force, but the complete set of events is not completely understood. In theory orthodontic tooth movement can be achieved after applying a very light force as the physiological forces that positions the dentition naturally; in this context bone remodeling occurs; these ideal concept is not always achieved, in fact orthodontic forces cause certain tissue damage. The optimum forces for orthodontic tooth movement activate the maximum tissue and cellular response without damaging and maintaining the periodontal ligament integrity and tooth structure. It has been postulated that the remodeling of periodontal tissue is the key element for orthodontic tooth movement. Orthodontists must apply forces high enough to stimulate cellular activity without diminishing blood and oxygen supply [1]. This is a very difficult objective to achieve, because orthodontists deal with frictional resistance, an element ignored in the past. Coulomb and Morin are recognized by the classical work of friction, they reported that when an object slides or tries to slide over another one, the force that resists that tendency is called friction. The force that acts between surfaces at rest is called static friction, and the frictional forces acting between surfaces in motion is called kinetic friction $[2,3]$.

Since 1960 Stoner reported the inefficiency of orthodontic systems, an applied force will not be correctly directed to the teeth and part of it will be lost because of friction, so it is very difficult to control or quantify the amount of it [4]. In recent years there has been an increment in the research of frictional forces in orthodontic systems, because of the importance and repercussion in clinical practice. Different variables can directly or indirectly influence frictional forces, some related to arch wires (composition, stiffness, etc.), some related to the bracket (dimensions, fabrication process, composition, design, force and method of ligation, etc.), and some others related to the system (inter bracket distance) or intraoral environment (saliva, plaque, temperature, masticatory forces, etc.) [5-7]. Different authors have evaluated these variables, but unfortunately there is no standardization of the methodology required to evaluate frictional resistance as every author designs an experimental model based on the objectives of the study, so the results cant be compared between them.

The force of ligation influences frictional resistance, it has been estimated that can range from 50 to 735 grams and the most common methods used today are: elastomeric ties, low friction elastomeric ties, metallic ligature and self- ligating brackets (passive or active) $[8,9]$. The ligation method that enhances maximum biological response after applying an orthodontic force enough to overcome frictional resistance and stay in the range of optimum force levels is ideal, the method of ligation that generates the lowest frictional resistance, will cause an efficient and biologically satisfactory orthodontic tooth movement.

\section{Materials and Methods}

Five different methods of ligation were compared in this study: elastomeric ties, low friction elastomeric ties, stainless steel ligature, active self-ligating and passive self-ligating brackets. Conventional twin brackets 0.018 " $\times 0.025$ " slot (Gemini twin bracket Roth prescription, 3M Unitek, Monrovia California) were used for the elastomeric ties, low friction elastomeric ties (Super Slicks TP Orthodontics, La Porte, IN) stainless steel ligature (new brackets were used for each method of ligation) and two active self-ligating brackets were tested, Time (American Orthodontics, Sheboygan, WI) and In-Ovation R (Dentsply GAC International, New York), the passive self-ligating bracket was Damon SL (Ormco, Orange, CA). The brackets were coupled with

*Corresponding author: Armando Montesinos F, MSc, Department of Orthodontics, Postgraduate Studies and Research Division, Odontology Faculty National Autonomous University of Mexico, Tel: (525) 555542429; E-mail: amfortod_@hotmail.com; info@montesinosortodoncia.com.mx

Received June 05, 2015; Accepted June 28, 2015; Published July 08, 2015

Citation: Armando Montesinos F (2015) A Comparative Study of Static and Kinetic Frictional Resistance during the Sliding of Arch Wires through Orthodontic Brackets, using Different Methods of Ligation, in the Dry State. Bioceram Dev Appl 5: 085. doi:10.4172/2090-5025.1000085

Copyright: (c) 2015 Armando Montesinos F. This is an open-access article distributed under the terms of the Creative Commons Attribution License, which permits unrestricted use, distribution, and reproduction in any medium, provided the original author and source are credited. 
Citation: Armando Montesinos F (2015) A Comparative Study of Static and Kinetic Frictional Resistance during the Sliding of Arch Wires through Orthodontic Brackets, using Different Methods of Ligation, in the Dry State. Bioceram Dev Appl 5: 085. doi:10.4172/2090-5025.1000085

Page 2 of 8

$0.016 "$ and $0.016 " \times 0.022 "$ stainless steel preformed arch wires (ovoid form Ortho III, 3M Unitek) upper and lower depending of the set of brackets tested.

Two metallic bases were designed simulating the form and dimensions of a leveled and aligned upper and lower half arch using the Ortho form III (3M Unitek, Monrovia, CA). An upper right central, lateral, cuspid, first and second bicuspids were bonded to the upper metallic base at the same height and in the center of what it would correspond to the midline of each corresponding leveled and aligned tooth. This was achieved by using an upper 0.018 " $\times 0.025$ " stainless steel preformed arch wire, the mesio distal width and center of each tooth was marked on the wire based on the measures reported by Howe and McNamara [10]. Each bracket was fixed to the arch wire by an elastomeric tie in the middle of what it would correspond the center of each tooth. In this way several variables were controlled that could affect the results, such as different heights between brackets, the in-out dimensions of each bracket base, different values of angulation and/or torque. The bracket prescription was expressed by using full size arch wire $(0.018 " \times 0.025$ "), when bonded to the metallic bases, the arch wires would be in a passive state, like a clinical condition of a leveled and aligned arch, therefore we could evaluate method of ligation without undesirable variables. The same was made for the lower metallic base, based on the lower arch form and tooth values. After testing each system the brackets were removed and new ones were fixed for the next method of ligation to be tested (Figure 1).

Specific devices were designed and made to fix the specimens to a Universal Testing Machine with the objective that the load cell of the electronic dynamometer would be always fixed in the same position.

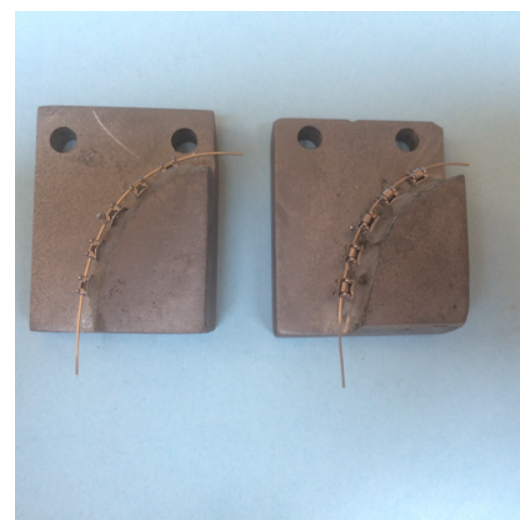

Figure 1: Metallic bases upper and lower with brackets bonded, archwire ligated to brackets, ready to be tested.

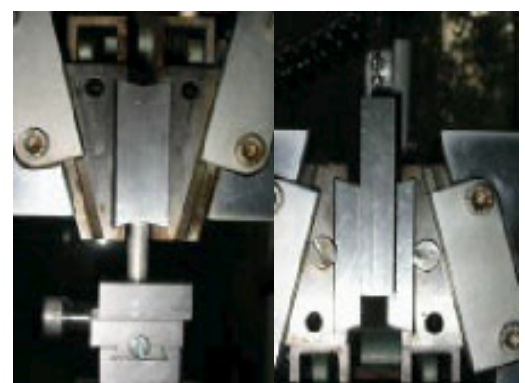

Figure 2: Special guides to fix the metallic bases to the universal testing machine.

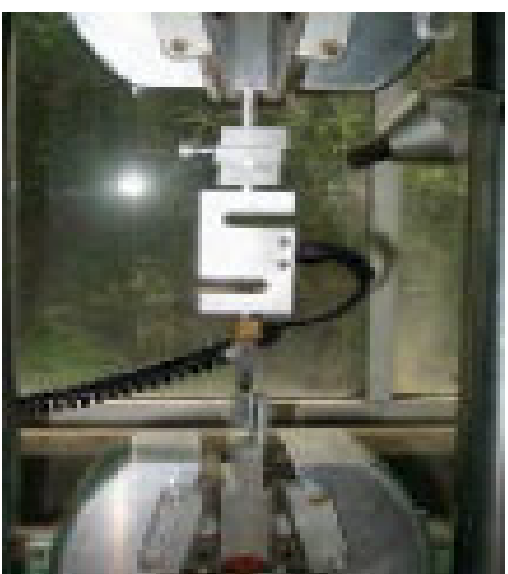

Figure 3: Testing apparatus.

A special clamp was also designed to hold the arch wires to be slide through the brackets, and a rail system to fix the cell on it, in order to adjust the parallelism if needed, eliminating any cantilever effect, that could influence the results (Figure 2).

The objectives of the design and fabrication of the metallic bases were: - to simulate aligned dental arches, so the brackets could be fixed to them, -to use a rigid material so the readings were from the resistance to sliding between arch wires and brackets and not to the deformation of the bases as it could happen when using acrylic bases or plexi glass. Lack of reproducibility is a common problem in several studies, the specimens were fixed always in the same position for every test, this was accomplished by fabricating and using the metallic insertion guides and if there was a slight lack of parallelism between the clamp and the arch wire it was adjusted with the aligning device eliminating any cantilever effect. The method of bonding the brackets to the metallic bases had the objective of obtaining a simulated aligned half arch, so any arch wire engaged to the brackets would be in a passive state, therefore we could analyze purely the resistance to sliding between the arch wires and brackets depending only by the method of ligation, and not obtaining erroneous readings caused by undesirable variables.

Thirty upper stainless steel arch wires Ortho III (3M Unitek) 0.016" and 0.016 " $\times 0.022$ " were cut $6 \mathrm{~mm}$ from the midline (the segment with the midline mark and the $6 \mathrm{~mm}$ from it was the part of the arch wire fixed to the brackets). The same procedure was made for 30 lower stainless steel arch wires Ortho III (3M Unitek) 0.016 " and 0.016 " $\times$ 0.022 ". A Universal Testing Machine was used in the experiment; the upper half arch was fixed in the testing apparatus previously described. Five 0.016 " and five 0.016 " $\times 0.022$ " upper arch wires were tested. It was recorded the tensile charge needed to slide the arch wires through the brackets at the speed of $5 \mathrm{~mm} / \mathrm{min}$ from 0 seconds to 1 minute, so the total of sliding was $5 \mathrm{~mm}$; the same was made with the lower brackets with the corresponding arch wires and all the methods of ligation tested (Figure 3).

The elastomeric ties and low friction ties were tied with a mosquito plier, the stainless steel ligature was tied with a tying pencil, the Time, in-ovation and Damon SL brackets were opened and closed by the instrument recommended by the manufacturer. Special conditions were required to test the low friction elastomeric ties (Super Slick, TP Orthodontics, La Porte, IN), the same reported by the manufacturer [11]. Once the arch wires were tied with the low friction ties, the half 
Citation: Armando Montesinos F (2015) A Comparative Study of Static and Kinetic Frictional Resistance during the Sliding of Arch Wires through Orthodontic Brackets, using Different Methods of Ligation, in the Dry State. Bioceram Dev Appl 5: 085. doi:10.4172/2090-5025.1000085

Page 3 of 8

arches were immersed in natural water for 2 minutes before fixed to the testing apparatus.

\section{Data Acquisition}

The load cell registered the force level needed to move the arch wires through the brackets and these values were stored on a computer by the Mecmesin Dataplot software (Mecmesin, United Kingdom).

\section{Statistical analysis}

The data obtained was analyzed with the SPSS program V.19 (IBM) first using all data acquired in the minute of testing, making the descriptive statics of each group depending of the method of ligation, dimensions of the arch wire, and half arch (upper or lower), then a complete randomized designed (one way) ANOVA was used to test the significant differences between the different methods of ligation. This was followed by a Least Significant Difference (LSD) post hoc test to determine differences between the different groups. Then the same was performed for static frictional resistance and for kinetic frictional resistance at $1 \mathrm{~mm}, 2 \mathrm{~mm}, 3 \mathrm{~mm}, 4 \mathrm{~mm}$ and $5 \mathrm{~mm}$ of sliding.

\section{Results}

The results of this study showed significant different frictional resistance generated by the different methods of ligation. For the 0.016 " arch wires there was statistical significant difference between them. The method of ligation that generated higher frictional resistance values with statistical difference to the lower was: elastomeric ties, low friction elastomeric ties, metallic ligature, and at last the self-ligating brackets, there was no statistical difference between the self-ligating brackets. With the 0.016 " $\times 0.022$ " lower arch wire the method of ligation that generated higher frictional resistance to the lower was: elastomeric ties, low friction elastomeric ligatures, metallic ligature, Time and In-Ovation $\mathrm{R}$ self-ligating brackets (no statistical difference between them), and at last Damon SL. With the 0.016 " $\times 0.022$ " upper arch wire the method of ligation that generated higher frictional resistance to the lower was: elastomeric ties, low friction elastomeric ties, metallic ligature, Time and at last In-Ovation R and Damon SL self-ligating brackets (no statistical difference between them) (Figure 4 and Tables 1 and 2).

Static frictional resistance with the 0.016 " and $0.016 " \times 0.022$ " upper and lower arch wires, the method of ligation that generated higher frictional resistance to the lower was elastomeric ties, low friction elastomeric ties, metallic ligature, and at last the self-ligating brackets, existing no statistical difference between the self-ligating brackets (Figure 5 and Tables 3 and 4).

Kinetic frictional resistance with the 0.016 " upper and lower, 0.016 " $\times 0.022$ " lower and at $1 \mathrm{~mm}$ and $2 \mathrm{~mm}$ of sliding with the $0.016 " \times 0.022$ " arch wires, the method of ligation that generated higher frictional resistance to the lower was: elastomeric ties, low friction elastomeric ties, metallic ligature, and at last the self-ligating brackets, existing no statistical difference between the self-ligating brackets. At 3, 4 and 5 $\mathrm{mm}$ of sliding the method of ligation that generated higher frictional resistance to the lower was: elastomeric ties, low friction elastomeric ties, metallic ligature, Time self-ligating bracket, and at last In-Ovation
A

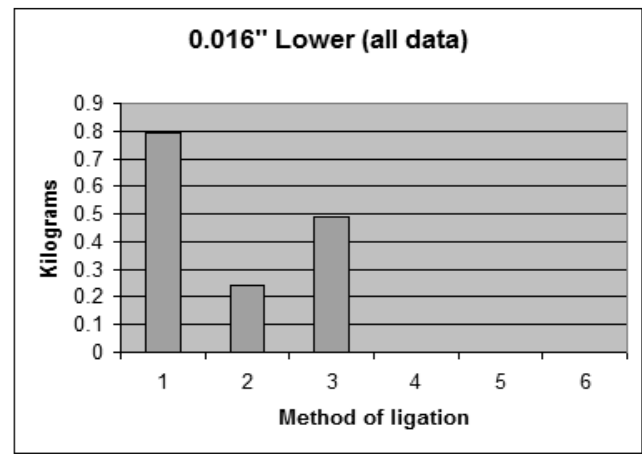

$\mathrm{C}$

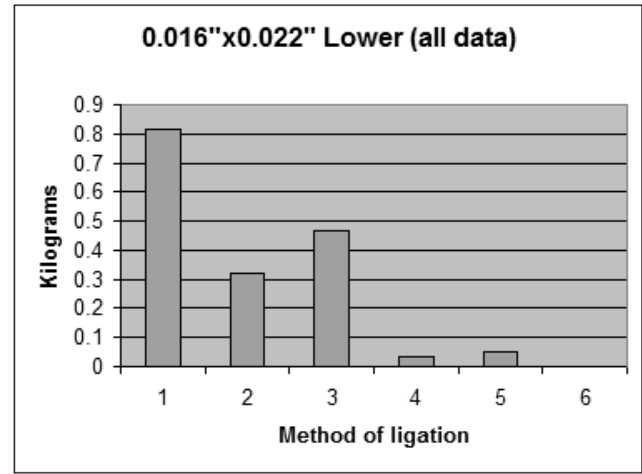

B

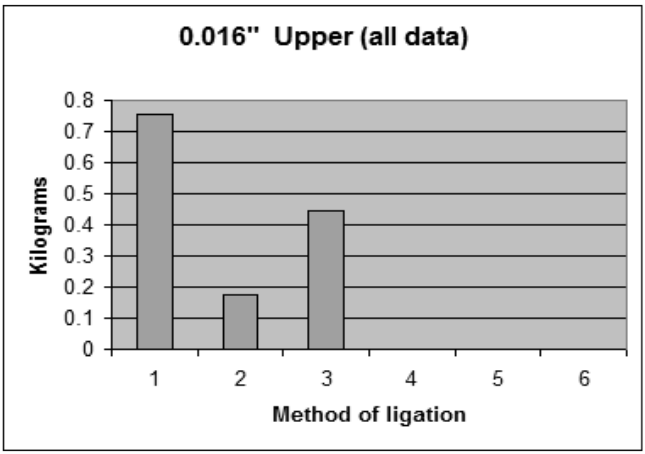

$\mathrm{D}$

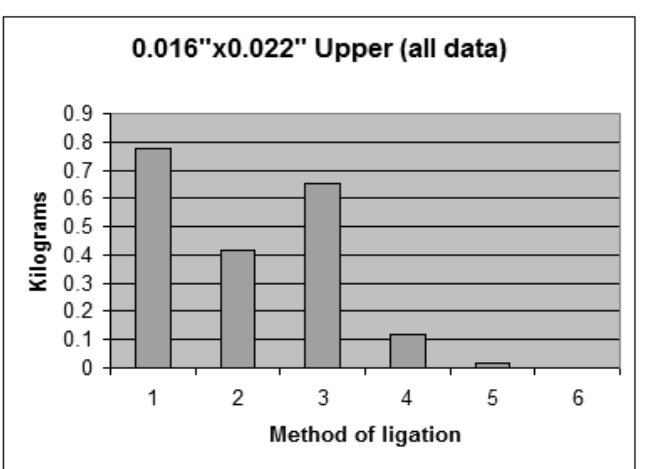

Figure 4: Mean frictional Resistance in kilograms using all data obtained in the minute of testing by wire size, upper and lower. $1=$ =Elastomeric ties, 2=Metallic ligature, 3=Low friction elastomeric ties, 4=Time, 5=In-Ovation R, 6=Damon SL. 
Citation: Armando Montesinos F (2015) A Comparative Study of Static and Kinetic Frictional Resistance during the Sliding of Arch Wires through Orthodontic Brackets, using Different Methods of Ligation, in the Dry State. Bioceram Dev Appl 5: 085. doi:10.4172/2090-5025.1000085

Page 4 of 8

\begin{tabular}{|c|c|c|c|c|c|c|c|c|c|}
\hline \multirow[b]{3}{*}{ Elastomeric ties } & \multirow{3}{*}{$\begin{array}{l}\mathbf{N} \\
5\end{array}$} & \multirow{2}{*}{\multicolumn{2}{|c|}{$\begin{array}{l}\text { 0.016" Lower } \\
\text { Mean SD }\end{array}$}} & \multirow{2}{*}{\multicolumn{2}{|c|}{$\begin{array}{l}\text { 0.016" Upper } \\
\text { Mean SD }\end{array}$}} & \multirow{2}{*}{\multicolumn{2}{|c|}{$\begin{array}{c}0.016 " \times 0.022 " \text { Lower } \\
\text { Mean SD }\end{array}$}} & \multirow{2}{*}{\multicolumn{2}{|c|}{$\begin{array}{c}0.016 " \times 0.022 " \text { Upper } \\
\text { Mean SD }\end{array}$}} \\
\hline & & & & & & & & & \\
\hline & & 0.795 & 0.11 & 0.753 & 0.088 & 0.815 & 0.113 & 0.777 & 0.082 \\
\hline Metalic ligature & 5 & 0.2427 & 0.24 & 0.175 & 0.036 & 0.323 & 0.069 & 0.416 & 0.075 \\
\hline $\begin{array}{l}\text { Low friction } \\
\text { elastomeric ties }\end{array}$ & 5 & 0.4917 & 0.49 & 0.443 & 0.077 & 0.467 & 0.08 & 0.655 & 0.109 \\
\hline Time & 5 & 0 & 0 & 0 & 0 & 0.036 & 0.016 & 0.119 & 0.041 \\
\hline In-Ovation & 5 & 0 & 0 & 0 & 0 & 0.048 & 0.019 & 0.015 & 0.008 \\
\hline Damon SL & 5 & 0 & 0 & 0 & 0 & 0 & 0 & 0 & 0 \\
\hline
\end{tabular}

$\mathrm{p}<0.05 \mathrm{~N}:$ Number of arch wires tested

Table 1: Mean and SD of frictional resistance in kilograms using all data obtained in the minute of testing by wire size, upper and lower.

\begin{tabular}{|c|c|c|c|c|}
\hline & 0.016" Lower & 0.016" Upper & $0.016 \times 0.022$ " Lower & $0.016 " \times 0.022$ " Upper \\
\hline $\mathbf{F}$ & 2006.72 & 2284.1 & 1524.13 & 1555.84 \\
\hline
\end{tabular}

$\mathrm{P}<0.001$

Table 2: One-way ANOVA using all data obtained in one minute of testing by wire size, upper and lower.

A

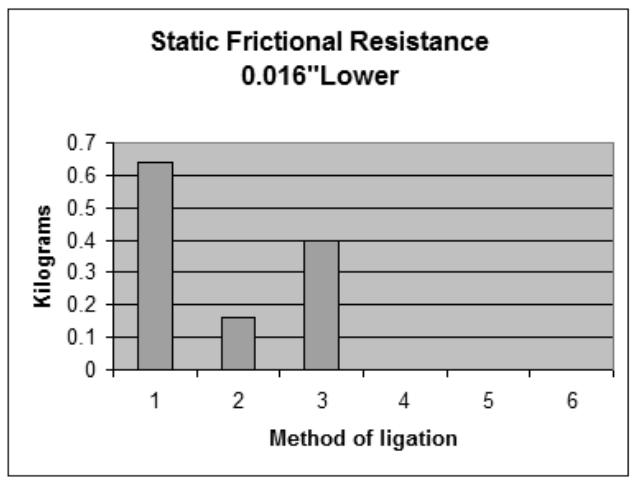

$\mathrm{C}$

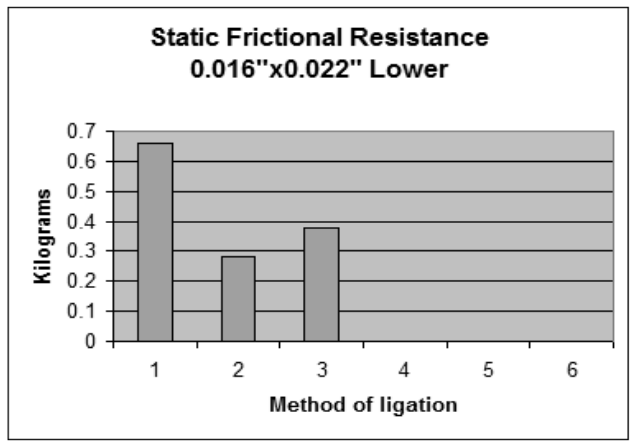

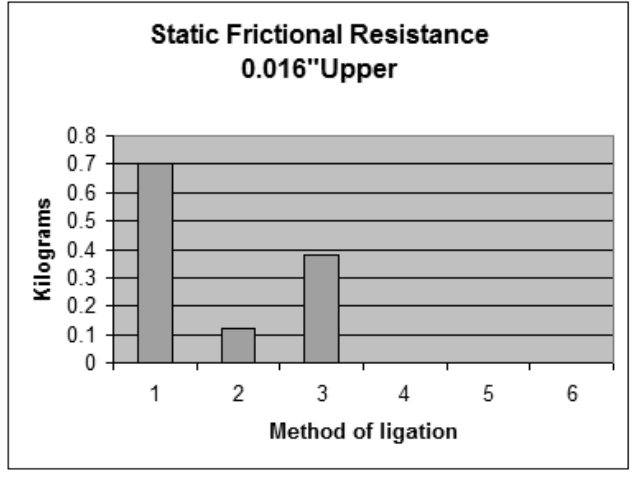

$\mathrm{D}$

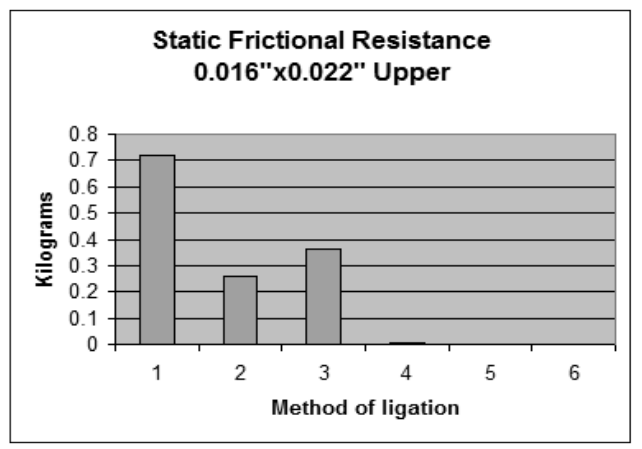

Figure 5: Mean of static frictional resistance in kilograms using all data obtained in the minute of testing by wire size, upper and lower.1=Elastomeric ties, 2=Metallic ligature, 3=Low friction elastomeric ties, 4=Time, 5=In-Ovation R, 6=Damon SL.

R and Damon SL self-ligating brackets existing no statistical difference between the last two (Figure 6 and Tables 5 and 6 ).

Low friction elastomeric ties generated $37 \%$ less static frictional resistance than the generated by regular elastomeric ties, metallic ligature $75 \%$ less and all self-ligating brackets $100 \%$ less for the 0.016 " lower stainless steel arch wires. With the 0.016" upper stainless steel arch wires low friction elastomeric ties generated $46 \%$ less static frictional resistance than the generated by regular elastomeric ties, metallic ligature $83 \%$ less and all self-ligating brackets $100 \%$ less. With the $0.016 " \times 0.022$ " lower stainless steel arch wires low friction elastomeric ties generated $42 \%$ less static frictional resistance than the generated by regular elastomeric ties, metallic ligature $61 \%$ less and all self-ligating brackets $100 \%$ less. With the 0.016 " $\times 0.022$ " upper stainless steel arch wires low friction elastomeric ties generated $22 \%$ less static frictional resistance than the generated by regular elastomeric 
Citation: Armando Montesinos F (2015) A Comparative Study of Static and Kinetic Frictional Resistance during the Sliding of Arch Wires through Orthodontic Brackets, using Different Methods of Ligation, in the Dry State. Bioceram Dev Appl 5: 085. doi:10.4172/2090-5025.1000085

Page 5 of 8

\begin{tabular}{|c|c|c|c|c|c|c|c|c|c|}
\hline \multirow[b]{3}{*}{ Elastomeric ties } & \multirow{3}{*}{$\begin{array}{l}\mathbf{N} \\
5\end{array}$} & \multirow{2}{*}{\multicolumn{2}{|c|}{$\begin{array}{l}0.016 " \text { Lower } \\
\text { Mean SD }\end{array}$}} & \multirow{2}{*}{\multicolumn{2}{|c|}{$\begin{array}{l}\text { 0.016" Upper } \\
\text { Mean SD }\end{array}$}} & \multirow{2}{*}{\multicolumn{2}{|c|}{$\begin{array}{c}0.016 " \times 0.022 " \text { Lower } \\
\text { Mean SD }\end{array}$}} & \multirow{2}{*}{\multicolumn{2}{|c|}{$\begin{array}{c}0.016 " \times 0.022 " \text { Upper } \\
\text { Mean SD }\end{array}$}} \\
\hline & & & & & & & & & \\
\hline & & 0.64 & 0.13 & 0.7 & 0.0707 & 0.66 & 0.114 & 0.72 & 0.0836 \\
\hline Metalic ligature & 5 & 0.16 & 0.11 & 0.12 & 0.0447 & 0.28 & 0.0547 & 0.26 & 0.167 \\
\hline $\begin{array}{l}\text { Low friction } \\
\text { elastomeric ties }\end{array}$ & 5 & 0.4 & 0.1 & 0.38 & 0.0447 & 0.38 & 0.0447 & 0.36 & 0.151 \\
\hline Time & 5 & 0 & 0 & 0 & 0 & 0 & 0 & 0.004 & 0.08 \\
\hline In-Ovation & 5 & 0 & 0 & 0 & 0 & 0 & 0 & 0 & 0 \\
\hline Damon SL & 5 & 0 & 0 & 0 & 0 & 0 & 0 & 0 & 0 \\
\hline
\end{tabular}

$\mathrm{p}<0.05 \mathrm{~N}$ : Number of arch wires tested

Table 3: Mean and SD of static frictional resistance in kilograms by wire size, upper and lower.

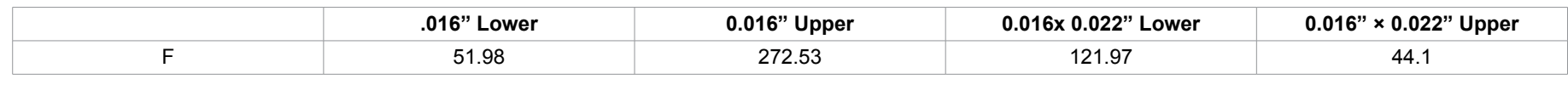

$p<0.001$

Table 4: One-way ANOVA for static frictional resistance by wire size, upper and lower.

A

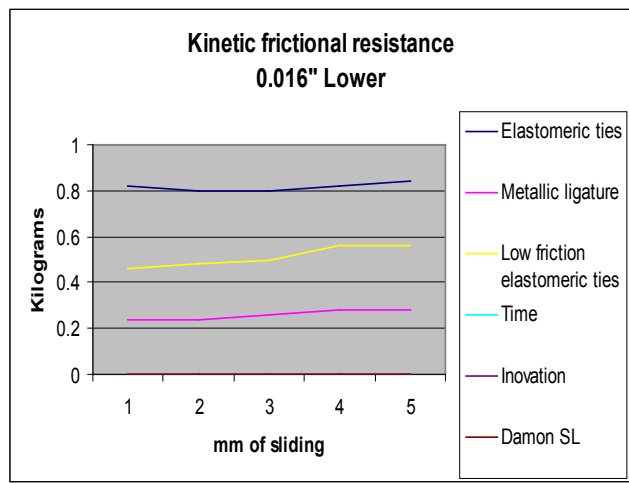

$\mathrm{C}$

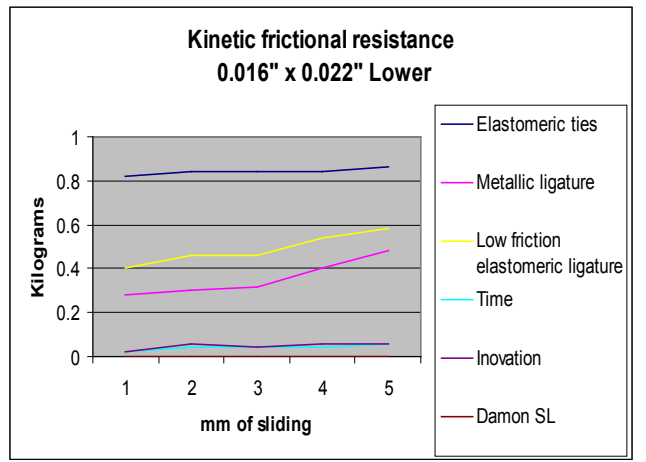

$\mathrm{B}$

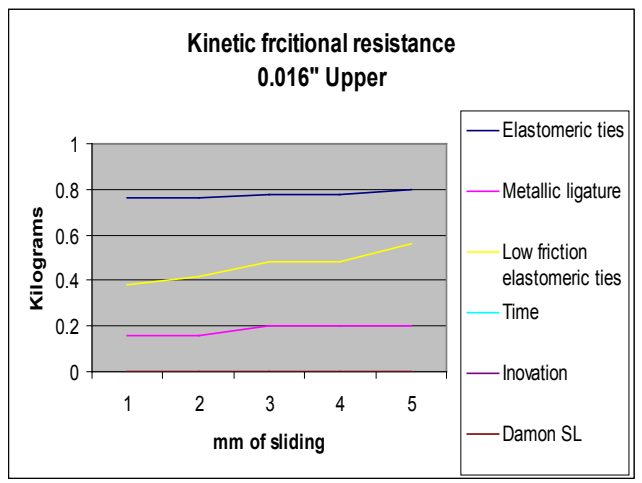

$\mathrm{D}$

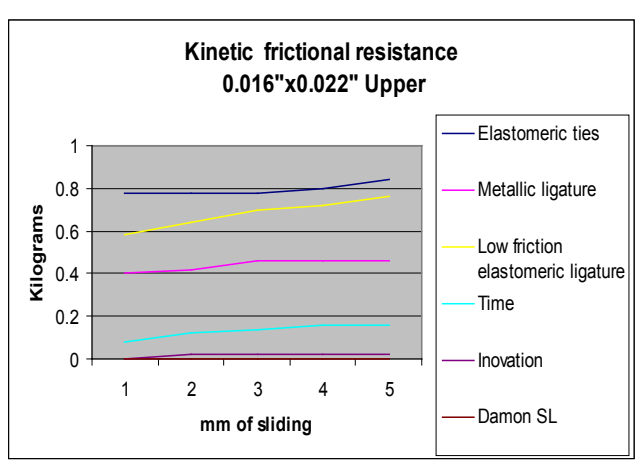

Figure 6: Mean of kinetic frictional resistance in kilograms by wire size, $\mathrm{mm}$ of sliding, upper and lower.

ties, metallic ligature $64 \%$ less, Time self-ligating brackets $94 \%$ and InOvation R and Damon SL self-ligating brackets $100 \%$ less.

Low friction elastomeric ties generated $48 \%$ less kinetic frictional resistance than the generated by regular elastomeric ties, metallic ligature $75 \%$ less and all self-ligating brackets $100 \%$ less for the 0.016 " lower stainless steel arch wires. With the 0.016 " upper stainless steel arch wires low friction elastomeric ties generated 50\% less kinetic frictional resistance than the generated by regular elastomeric ties, metallic ligature $77 \%$ less and all self-ligating brackets $100 \%$ less. With the 0.016 " $\times 0.022$ " lower stainless steel arch wires low friction elastomeric ties generated $48 \%$ less kinetic frictional resistance than the generated by regular elastomeric ties, metallic ligature $67 \%$ less, Time brackets $93 \%$ less, In-Ovation R brackets 95\% less and Damon SL brackets $100 \%$ less. With the 0.016 " $\times 0.022$ " upper stainless steel arch wires low friction elastomeric ties generated $26 \%$ less kinetic frictional 
Citation: Armando Montesinos F (2015) A Comparative Study of Static and Kinetic Frictional Resistance during the Sliding of Arch Wires through Orthodontic Brackets, using Different Methods of Ligation, in the Dry State. Bioceram Dev Appl 5: 085. doi:10.4172/2090-5025.1000085

Page 6 of 8

\begin{tabular}{|c|c|c|c|c|c|c|c|c|c|c|}
\hline \multirow{3}{*}{\begin{tabular}{|l} 
Elastomeric ties \\
\end{tabular}} & \multirow{3}{*}{$\begin{array}{l}\mathrm{N} \\
5\end{array}$} & \multirow{3}{*}{$\begin{array}{c}\begin{array}{c}\text { mm of } \\
\text { sliding }\end{array} \\
1 \mathrm{~mm}\end{array}$} & \multirow{2}{*}{\multicolumn{2}{|c|}{$\begin{array}{l}\text { 0.016" Lower } \\
\text { Mean SD }\end{array}$}} & \multirow{2}{*}{\multicolumn{2}{|c|}{$\begin{array}{l}\text { 0.016" Upper } \\
\text { Mean SD }\end{array}$}} & \multirow{2}{*}{\multicolumn{2}{|c|}{$\begin{array}{c}0.016 " \times 0.022 " \text { Lower } \\
\text { Mean SD }\end{array}$}} & \multirow{2}{*}{\multicolumn{2}{|c|}{$\begin{array}{c}0.016 " \times 0.022 " \text { Upper } \\
\text { Mean SD }\end{array}$}} \\
\hline & & & & & & & & & & \\
\hline & & & 0.82 & 0.16 & 0.76 & 0.05 & 0.82 & 0.13 & 0.78 & 0.04 \\
\hline \multirow{4}{*}{ Elastomeric ties } & & $2 \mathrm{~mm}$ & 0.8 & 0.12 & 0.76 & 0.08 & 0.84 & 0.15 & 0.78 & 0.04 \\
\hline & & $3 \mathrm{~mm}$ & 0.8 & 0.17 & 0.78 & 0.08 & 0.84 & 0.15 & 0.78 & 0.04 \\
\hline & & $4 \mathrm{~mm}$ & 0.82 & 0.16 & 0.78 & 0.01 & 0.84 & 0.15 & 0.8 & 0.03 \\
\hline & & $5 \mathrm{~mm}$ & 0.84 & 0.15 & 0.8 & 0.12 & 0.86 & 0.15 & 0.84 & 0.03 \\
\hline \multirow[t]{5}{*}{ Metallic ligature } & \multirow[t]{5}{*}{5} & $1 \mathrm{~mm}$ & 0.24 & 0.054 & 0.16 & 0.05 & 0.28 & 0.04 & 0.4 & 0.1 \\
\hline & & $2 \mathrm{~mm}$ & 0.24 & 0.054 & 0.16 & 0.05 & 0.3 & 0.07 & 0.42 & 0.1 \\
\hline & & $3 \mathrm{~mm}$ & 0.26 & 0.089 & 0.2 & 0.07 & 0.32 & 0.04 & 0.46 & 0.1 \\
\hline & & $4 \mathrm{~mm}$ & 0.28 & 0.1 & 0.2 & 0.07 & 0.4 & 0.16 & 0.46 & 0.1 \\
\hline & & $5 \mathrm{~mm}$ & 0.28 & 0.1 & 0.2 & 0.07 & 0.48 & 0.08 & 0.46 & 0.1 \\
\hline \multirow{5}{*}{$\begin{array}{l}\text { Low friction } \\
\text { elastomeric ties }\end{array}$} & 5 & $1 \mathrm{~mm}$ & 0.46 & 0.114 & 0.38 & 0.04 & 0.4 & 0.07 & 0.58 & 0.16 \\
\hline & & $2 \mathrm{~mm}$ & 0.48 & 0.13 & 0.42 & 0.04 & 0.46 & 0.07 & 0.64 & 0.08 \\
\hline & & $3 \mathrm{~mm}$ & 0.5 & 0.08 & 0.48 & 0.08 & 0.46 & 0.04 & 0.7 & 0.14 \\
\hline & & $4 \mathrm{~mm}$ & 0.56 & 0.08 & 0.48 & 0.08 & 0.54 & 0.08 & 0.72 & 0.1 \\
\hline & & $5 \mathrm{~mm}$ & 0.56 & 0.08 & 0.56 & 0.05 & 0.58 & 0.04 & 0.76 & 0.11 \\
\hline \multirow[t]{5}{*}{ Time } & 5 & $1 \mathrm{~mm}$ & 0 & 0 & 0 & 0 & 0.02 & 0.04 & 0.08 & 0.13 \\
\hline & & $2 \mathrm{~mm}$ & 0 & 0 & 0 & 0 & 0.04 & 0.08 & 0.12 & 0.13 \\
\hline & & $3 \mathrm{~mm}$ & 0 & 0 & 0 & 0 & 0.04 & 0.08 & 0.14 & 0.11 \\
\hline & & $4 \mathrm{~mm}$ & 0 & 0 & 0 & 0 & 0.04 & 0.08 & 0.16 & 0.08 \\
\hline & & $5 \mathrm{~mm}$ & 0 & 0 & 0 & 0 & 0.06 & 0.08 & 0.16 & 0.08 \\
\hline \multirow[t]{5}{*}{ In-Ovation } & 5 & $1 \mathrm{~mm}$ & 0 & 0 & 0 & 0 & 0.02 & 0.04 & 0 & 0 \\
\hline & & $2 \mathrm{~mm}$ & 0 & 0 & 0 & 0 & 0.06 & 0.05 & 0.02 & 0.04 \\
\hline & & $3 \mathrm{~mm}$ & 0 & 0 & 0 & 0 & 0.04 & 0.05 & 0.02 & 0.04 \\
\hline & & $4 \mathrm{~mm}$ & 0 & 0 & 0 & 0 & 0.06 & 0.05 & 0.02 & 0.04 \\
\hline & & $5 \mathrm{~mm}$ & 0 & 0 & 0 & 0 & 0.06 & 0.05 & 0.02 & 0.04 \\
\hline \multirow[t]{5}{*}{ Damon SL } & \multirow[t]{5}{*}{5} & $1 \mathrm{~mm}$ & 0 & 0 & 0 & 0 & 0 & 0 & 0 & 0 \\
\hline & & $2 \mathrm{~mm}$ & 0 & 0 & 0 & 0 & 0 & 0 & 0 & 0 \\
\hline & & $3 \mathrm{~mm}$ & 0 & 0 & 0 & 0 & 0 & 0 & 0 & 0 \\
\hline & & $4 \mathrm{~mm}$ & 0 & 0 & 0 & 0 & 0 & 0 & 0 & 0 \\
\hline & & $5 \mathrm{~mm}$ & 0 & 0 & 0 & 0 & 0 & 0 & 0 & 0 \\
\hline
\end{tabular}

$\mathrm{p}<0.05 \mathrm{~N}$ : Number of arch wires tested

Table 5: Mean and SD of kinetic frictional resistance in kilograms by wire size, $\mathrm{mm}$ of sliding, upper and lower

\begin{tabular}{|c|c|c|c|c|}
\hline mm of sliding & $\mathbf{0 . 0 1 6}$ " Lower & 0.016" Upper & $\begin{array}{c}\mathbf{0 . 0 1 6} \times \mathbf{0 . 0 2 2} \\
\text { Lower }\end{array}$ & $\begin{array}{c}\mathbf{0 . 0 1 6} \text { ” } \times \\
\mathbf{0 . 0 2 2} \text { ' Upper }\end{array}$ \\
\hline $\mathbf{1} \mathbf{~ m m}$ & 77.65 & 215.04 & 110.64 & 58.6 \\
\hline $\mathbf{2} \mathbf{~ m m}$ & 93.07 & 221.69 & 75.81 & 72.4 \\
\hline $\mathbf{3} \mathbf{~ m m}$ & 62.49 & 165.32 & 81.8 & 71.4 \\
\hline $\mathbf{4} \mathbf{~ m m}$ & 77.25 & 165.32 & 81.9 & 106.01 \\
\hline $\mathbf{5} \mathbf{~ m m}$ & 97.51 & 153.39 & 86.51 & 105.31 \\
\hline
\end{tabular}

$\mathrm{p}<0.001$

Table 6: One-way ANOVA for kinetic frictional resistance by wire size, $\mathrm{mm}$ of sliding, upper and lower.

resistance than the generated by regular elastomeric ties, metallic ligature $49 \%$ less, Time self-ligating brackets $92 \%$ less and In-Ovation $\mathrm{R}$ and Damon SL self-ligating brackets 100\% less.

\section{Discussion}

This experimental model as all in vitro studies cannot reproduce the complete chain of phenomena that happens during orthodontic tooth movement. This model represents an specific clinical situation to be able to evaluate how much the method of ligation influence frictional resistance to sliding and can not reproduce all clinical conditions like, chewing forces, plaque, temperature, humidity, etc. By evaluating the different methods of ligation used today by the orthodontist the results showed differences between the frictional resistances to sliding generated by them. Frictional resistance is a complex interaction between the bracket, arch wires, method of ligation, etc., so the results of this article should be applied with caution. It is very important to remember that elastomeric ties loose their strength by $50-70 \%$ during the first $24 \mathrm{~h} \mathrm{[12]} \mathrm{this} \mathrm{study} \mathrm{tested} \mathrm{the} \mathrm{ties} \mathrm{right} \mathrm{after} \mathrm{tied} \mathrm{to} \mathrm{the} \mathrm{brackets.}$ Low friction elastomeric ties reduce significantly frictional resistance compared to regular elastomeric ties, Hain et al. found similar results when comparing these low friction elastomeric ties with other method of ligation [13], in the contrary Griffiths et al. and Pattan et al. found that super slick ties demonstrated greater frictional resistance to sliding $[14,15]$, may be because differences in the experimental model.

Low friction elastomeric ties (Super slick, TP Orthodontics) represent a good alternative to have control and lowering the values of frictional resistance, in actual orthodontic systems clinicians have to sacrifice "control" of tooth movement to decrease frictional resistance.

Although the objectives and methodology of this study are different to the ones used by other authors the results are similar. Voudouris reported that the method of ligation with higher frictional resistance values was with elastomeric ties, metallic ligature, active self-ligating bracket and at last passive self-ligating bracket [16]. Berger observed more frictional resistance with the use of elastomeric ties followed by 
Citation: Armando Montesinos F (2015) A Comparative Study of Static and Kinetic Frictional Resistance during the Sliding of Arch Wires through Orthodontic Brackets, using Different Methods of Ligation, in the Dry State. Bioceram Dev Appl 5: 085. doi:10.4172/2090-5025.1000085

Page 7 of 8

metallic ligature and at last the Speed a self-ligating bracket [17]. Kapur compared conventional brackets using elastomeric ties vs. self-ligating brackets, the results showed a significant difference, the conventional brackets with elastomeric ties generated 15 times more frictional resistance than self-ligating brackets [18], as also observed by Sims when comparing the frictional resistance generated by the Activa selfligating bracket with conventional methods of ligation [19]. Prassana found that the method of ligation that generated more frictional resistance was with the use of elastomeric ties, followed by metallic ligature and frictional resistance was reduced with the use of the selfligating brackets tested in the study (Activa, Edgelock and Speed) [20].

Kussy and Thorstenson tested the different methods of ligation and second order angulations, generating very little frictional resistance or none, especially with the passive self-ligating brackets compared to the conventional ligation methods $[21,22]$. Smith used a canine retraction model and found that the conventional brackets generated significant higher frictional resistance values than the self-ligating brackets tested [23]. Khambay et al. [24], Budd et al. [25], Cordasco et al. [26] and Read-Ward et al. [27] also found significant lower frictional resistance with self-ligating brackets although differential experimental models were analyzed (different brackets, arch wires sizes and materials, angulations, etc.). In spite the different experimental models used selfligating brackets showed a dramatic reduction of frictional resistance, generating even lower values the passive self-ligating brackets than the active ones.

Frictional resistance and orthodontic tooth movement relationship must be studied and analyzed. Research should be directed to the biological model of orthodontic tooth movement and the influence of frictional resistance and the many variables that influence them. The new model should explain the different changes in the periodontal tissue, dental structure (pulp, dentin, cement, etc.) and the mechanisms and phenomena occurring in the arch wire-bracket interphase, when an orthodontic force is applied. Orthodontist must understand how frictional resistance affects the periodontal tissue remodeling and the changes that occur in the tooth structure and vice versa, so the new model must be established based on the following four elements: orthodontic force-tooth-periodontal tissue-frictional resistance.

The arch wire-bracket interphase is a very important area to be considered but it is not the only one where frictional resistance is present; frictional resistance is not only present between the vertical wall of the slot it is also present in the horizontal walls, depending also on the arch wire dimensions and configuration. The mechanisms related to frictional resistance are also developing in areas such as the contact of the arch wire and the method of ligation (metallic ligature, elastomeric tie, or even the clip or lid of a self-ligating bracket). It must be noted that as the orthodontist applies forces to each tooth far from its the center of resistance the resultant tooth movement has a tipping effect in different degrees, generating also new zones of contact where frictional resistance is occurring.

Orthodontic tooth movement is not continuous and harmonious, a tooth moves by "jigs" and "jogs", sporadically gyrating more in accord with the tectonic plate theory than a well-lubricated ball bearing [28]. Every orthodontic system must be analyzed in a tridimensional way; the total frictional resistance in a specific clinical situation is the result of an additive effect of the different areas of contact where frictional resistance is present.

Total resistance to sliding (TRS) in an orthodontic model is the result of the sum of the different frictional resistance generated in all areas of contact in a specific system:

\section{TRS $=$ Fr $1+\operatorname{Fr} 2+\operatorname{Fr} 3 \ldots$}

In which Frictional Resistance (FR n) of each zone is the result of the sum of the different phenomena involved:

$\mathrm{FR} n=\mathrm{CFR}+\mathrm{BI}+\mathrm{NO}+\mathrm{PL}+\mathrm{IR}+\mathrm{EPDU}$

CFR: Classic frictional resistance (Static and Kinetic)

BI: Binding

NO: Notching of the contact surfaces

PL: Plowing of the contact surfaces

IR: Interlocking of the asperities or roughness of the surfaces

EPDU: Elastic and plastic deformation of the unions between surfaces

Due to the lack of standardization of the methodology required to test frictional resistance, different authors have tested in very different ways depending of their objectives. Different models should be developed to test and analyze frictional resistance, so the results may be more accurate and can be compared more easily between different authors. This study suggests an experimental model to analyze the influence of the method of ligation in the conditions formerly explained before, it is suggested the development of new ones to simulate the different situations and conditions in clinical orthodontics such as wet state, temperature, periodontal ligament resistance, etc., although we cannot reproduce all of them in vitro.

Frictional resistance must not be considered as the villain in an orthodontic story, there must be considered two types of frictional resistance, the "undesirable" one as a result of an inefficient orthodontic system or not benefic for sliding mechanics, and the "desirable" frictional resistance that is needed to accomplish certain orthodontic tooth movements as torque, frictional resistance is required when orthodontist needs "control". For efficiency in sliding mechanics orthodontists must choose a frictionless system such as self-ligating brackets; the actual technological development has not designed a system that can provide "control" and a "frictionless mechanism" at the same time, although manufacturers sell their self-ligating brackets as a system to be frictionless with small arch wires to level, align and close spaces and to have control with larger arch wires by proposing and interactive or dual self-ligating bracket that is passive with small ach wires and active with larger arch wires. Further research is needed and new mechanisms must be designed to accomplish these objectives.

\section{Conclusions}

1. The method of ligation that generated the highest static frictional resistance values was with the use of elastomeric ties, followed by low friction elastomeric ties $>$ metallic ligature $>$ and at last self-ligating brackets for all archwires.

2. For static frictional resistance there is no difference between the use of an active and passive self-ligating bracket.

3. In this experimental model kinetic frictional resistance was always higher than static frictional resistance.

4. The method of ligation that generated the highest kinetic frictional resistance values was with the use of elastomeric ties, followed by low friction elastomeric ties $>$ metallic ligature $>$ and at last self-ligating brackets. 
Citation: Armando Montesinos F (2015) A Comparative Study of Static and Kinetic Frictional Resistance during the Sliding of Arch Wires through Orthodontic Brackets, using Different Methods of Ligation, in the Dry State. Bioceram Dev Appl 5: 085. doi:10.4172/2090-5025.1000085

5. Between the two different active self-ligating brackets used in this experimental model, Time brackets generates higher kinetic frictional resistance values than In-Ovation R Brackets.

6. The passive self-ligating brackets never generated frictional resistance in this experimental model.

\section{References}

1. Damon D (1998) The rationale, evolution and clinical application of the selfligating bracket. Clinical Orthodontics and Reserch 1: 52-61.

2. Palmer F (1951) Friction. Sci Am 184: 54-60.

3. Rabinowixz E (1995) Friction and wear of materials (2ndedn.) John Wiley and sons, Inc, USA.

4. Stoner MM (1960) Force control in clinical practice. Am J Orthod Dentofac Orthop 46: 163-68

5. Andreasen GF, Quevedo F (1970) Evaluation of frictional forces in the 0.022 " x 0.028 " edgewise bracket in vitro. J Biomech 151-160.

6. Angolkar P, Kapila S, Duncanson J, Nanda R (1990) Evaluation of friction between ceramic brackets and orthodontic wires of four alloys. Am J Orthod Dentofac Orthop 98: 499-506

7. Frank CA, Nikolai RJ (1980) A comparative study of frictional resistance between orthodontic bracket and arch wires. Am J Orthod 78: 593- 609.

8. Nicolls J (1968) Frictional forces in fixed orthodontic appliances. Dent Pract Dent Rec 18: 362-366.

9. Nanda RS, Ghosh J Biomechanical considerations in sliding mechanics. In Nanda R. Biomechanics in clinical orthodontics: W.B. Saunders, 1997: 188-217.

10. Howe RP, Mc Namara JA Jr, O'Connor KA (1983) An examination of dental crowding and its relationship to tooth size and arch dimension. Am J Orthod Dentofac Orthop 83: 363-73.

11. Devanathan D. Performance study of a low friction ligature. Investigation performed at the research laboratories of TP orthodontics. Inc. La Porte, Indiana.

12. Wong AK (1976) Orthodontic elastic material. Angle Orthod 46: 196-205

13. Hain M, Dhopatkar A, Rock P (2006) A comparison of different ligation methods on friction. Am J Orthod Dentofacial Orthop 130: 666-670.

14. Griffiths HS, Sherriff M, Ireland AJ (2005) Resistance to sliding with 3 types of elastomeric modules. Am J Orthod Dentofacial Orthop 127: 670-675.
15. Pattan SK, Peddu R, Bandaru SK, Lanka D, Mallavarapu K, et.al. (2014) Efficacy of Super Slick elastomeric $=$ modules in reducing friction during sliding a comparative in vitro study. J Contemp Dent Pract 15: 543-551.

16. Voudouris JC (1997) Interactive edgewise mechanisms: Form and fuction comparison with conventional edgewise brackets. Am J Orthod Dentofac Orthop 111: 119- 139.

17. Berger J (1990) The influence of the SPEED brackets self-ligating design on force levels in tooth movement: a comparative in vitro study. Am J Orthod Dentofac Orthop 97: 218- 28.

18. Kapur R, Sinha P (1998) Frictional resistance of the Damon SL bracket. Journa of Clinical Orthodontics 32: 485-489.

19. Sims A, Waters N, Birnie DA (1993) comparison of the forces required to produce tooth movement in vitro using two self-ligating brackets and a preadjusted bracket employing two types of ligation. Eur J Orthod 15: 377-85

20. Prassana K. A comparative study of conventional ligation and self-ligation bracket systems. Am J Orthod Dentofac Orthop 1994; 106: 472- 80

21. Thorstenson A G, Kusy R (2002) Comparison of resistance to sliding between different self-ligating brackets with second order angulation in the dry and saliva states. Am J Orthod Dentofac Orthop 121: 472-82.

22. Thorstenson AG (2001) Resistance to sliding of self-ligating brackets versus conventional stainless steel twin brackets with second order angulation in the dry and wet (saliva) states. Am J Orthod Dentofac Orthop 120: 361-70.

23. Smith DV, Rossow PE (2000) Frictional resistance evaluation of orthodontic brackets and arch wires with sliding mechanics using quantified simulation of canine retraction. Thesis abstracts in Am J Orthod Dentofac Orthop 120: 681.

24. Khambay B, Millett $D$, McHugh $S$. Evaluation of methods of arch wire ligation on frictional resistance. Eur J Orthod 2004 Jun: 26: 327-32.

25. Budd S, Daskalogiannakis J, Tompson BD (2008) A study of the frictional characteristics of four commercially available self-ligating bracket systems. Eur J Orthod 30: 645-53.

26. Cordasco G, Farronato G, Festa F, Nucera R, Parazzoli E, et al. (2009) In vitro evaluation of the frictional forces between brackets and archwire with three passive self-ligating brackets. Eur J Orthod. Dec; 31: 643-6.

27. Read-Ward GE, Jones S P, Davies EH (1997) A comparison of self-ligating and conventional orthodontic bracket systems. Br J Orthod 4: 309-17.

28. Kusy R, Whitley J (1997) Friction between different wire-bracket configuration and amaterials. In Seminars in Orthodontics 3: 166-177. 